\title{
ATIVIDADE ANTIOXIDANTE, TEOR DE FENÓIS E ATIVIDADE LARVICIDA FRENTE AO Aedes aegypti DE Vitex gardneriana Schauer
}

L.C.C. F. MONTEIRO (Licenciado em Química, bolsista ATP-B (CNPq))*; E. I. M. Araujo (Licenciado em Química, bolsista ATP-B (CNPq)); A. M. S. de Oliveira (Licenciada em Química, Bolsista DTI-C (CNPq)); L. A. Alves (Professor do Campus Apodi - Instituto Federal do Rio Grande do Norte, IFRN); L.M. Bertini (Professor do Campus Apodi - Instituto Federal do Rio Grande do Norte, IFRN)

*E-mail: laizacarlos@hotmail.com

\begin{abstract}
Resumo:
O início da utilização dos produtos naturais para os diversos fins se deu desde muitos tempo atrás, onde as primeiras civilizações já faziam uso dos mesmos para aliviar/curar doenças. O interesse da população por esses produtos vem crescendo cada vez mais. O presente trabalho tem o objetivo determinar a atividade antioxidante, 0 teor de fenóis totais e a atividade larvicida frente ao Aedes aegypti dos extratos em etanol e água da V. gardneriana Schauer, conhecida popularmente como jaramataia. Os resultados para os três testes foram satisfatórios, uma vez que para a atividade antioxidante a espécie vegetal apresentou uma $\mathrm{CI}_{50}$ de 82,60 ppm e 145,04 ppm para os extratos em etanol e água, respectivamente. O extrato em água se destacou quanto ao teor de fenóis, apresentando 92,85 mg de EAG/mg de extrato. Já para a atividade larvicida o único extrato que apresentou atividade, foi o em etanol com a $\mathrm{CL}_{50}$ de 369,1 ppm. De uma forma geral os resultados foram bastante promissores.
\end{abstract}

\section{Palavras-chave:}

Atividade Antioxidante; Fenóis; Atividade Larvicida; V. gardneriana Schauer.

Espaço reservado para organização do congresso. 


\section{INTRODUÇÃO}

Por muitos anos a única forma de alívio e/ou cura de doenças foi através da utilização de produtos naturais pelo homem, que usavam de suas próprias experiências e da observação do uso das plantas pelos animais (OLIVEIRA, 2006). Tais produtos não eram utilizados somente como medicamentos, mas também para os mais diversos fins, como o combate de pragas.

O Brasil, por apresentar uma flora bastante ampla e diversificada, é um país que se caracteriza por ser um bom local para a exploração dos produtos naturais, constituindo um vasto campo para o estudo farmacológico, como aponta os meios de comunicação através de documentários, reportagens e artigos científicos. Apesar de todo potencial, são necessários ainda estudos para que seja comprovado os relatos.

A diversidade molecular das plantas tem aumentado e estimulado a busca pelo conhecimento de seus metabolitos secundários, os quais são responsáveis pela síntese de grande parte dos compostos vegetais com atividade biológica. Grupos de compostos de estruturas complexas como alcalóides, terpenóides e compostos fenólicos, bem como seus derivados tem sido alvo de investigação a respeito de suas propriedades medicinais, aromáticas e curativas. A diversidade, em termos de estruturas e propriedades químicas, na qual essas substâncias são encontradas na natureza, podem servir para o desenvolvimento de um grande número de produtos naturais de interesse comercial (ALVES, 2001).

Diante do que foi exposto, o trabalho selecionou a planta Vitex gardneriana Schauer, conhecida popularmente como jaramataia, encontrada no sertão nordestino às margens de rios. A espécie vegetal é classificada dentro da família Lamiaceae, gênero Vitex (LIMA; FRANÇA, 2009) e é utilizada popularmente como anti-inflamatório e analgésico.

Desta forma, frente ao que foi exposto, o presente trabalho teve como objetivo determinar a atividade antioxidante, o teor de fenóis e ainda avaliar a atividade larvicida de extratos em etanol e aquoso de Vitex gardneriana Schauer frente ao Aedes aegypti.

\section{REVISÃO BIBLIOGRÁFICA}

\subsection{Produtos Naturais}

Com a finalidade de tratar diversas doenças, há milhares de anos atrás, as primeiras civilizações já faziam uso dos produtos naturais. Existem dois grandes grupos de compostos químicos produzidos pelas plantas, que são: os metabólitos primários e secundários. Os metabólitos primários são responsáveis pela produção de: celulose, lignina, proteínas, lipídios, açúcares e outras substâncias que realizam suas principais funções vitais (ALVES, 2001); já os metabólitos secundários, consistem num sistema de funções muito importantes para a sobrevivência e competição no ambiente (DIXON, 2001) e resultam ainda de substâncias de baixo peso molecular, às vezes produzidas em pequenas quantidades (ALVES, 2001).

Apesar dos grandes avanços observados na medicina moderna, eles continuam sendo utilizados e avalia-se que cerca de $30 \%$ de todos os medicamentos avaliados como agentes terapêuticos são derivados de metabólitos secundários (CALIXTO, 2005; VEIGA-JUNIOR; MELLO, 2008).

Os metabólitos secundários presentes nas espécies vegetais despertam grande interesse, não somente pelas atividades biológicas produzidas pelas mesmas em resposta aos estímulos do meio ambiente, mas também pela imensa atividade farmacológica desses compostos (ALVES, 2001).

A população aumentou seu interesse pelos produtos naturais principalmente por acreditarem que os mesmos são imunes ou possuírem poucos efeitos colaterais, e que aparentemente são eficazes em casos em que a medicina tradicional ainda não obteve resultado, o que nem sempre é confirmado pelas pesquisas científicas que avaliam a eficácia e a segurança, assim também como a garantia de qualidade na produção (CALIXTO, 2000; CARVALHO et al., 2008). Assim, cada vez mais a pesquisa cientifica vem ganhando espaço, visando encontrar e comprovar o uso de espécies vegetais que possuam componentes bioativos.

\subsection{Atividade Antioxidante $X$ Teor de Fenóis Totais}

Os antioxidantes, sejam eles naturais ou sintéticos, possuem grande estabilidade oxidativa devido a sua estrutura molecular, desempenhando assim papel fundamental na prevenção à oxidação de 
substâncias. Desta forma, podem ser definidos como qualquer substância que, quando comparado a um substrato oxidável, inibe ou retarda a oxidação desse substrato (AUST et al., 2001; HANDELMAN, 2001).

Uma pequena quantidade de evidências tem indicado o papel dos radicais livres como grandes culpados pelo envelhecimento precoce e pelas doenças degenerativas associadas ao envelhecimento como câncer, doenças cardiovasculares, catarata, declínio do sistema imune e disfunções cerebrais (AMES; GOLD; WILET, 1995; CHRISTEN, 2000; LANG; LOZANO, 1998; ROESLER et al., 2007).

Segundo Silva (2010) os compostos fenólicos (CF) são substâncias amplamente distribuídas na natureza, sendo que mais de 8000 compostos fenólicos já foram detectados em plantas. Esse grupo complexo faz parte dos constituintes de uma variedade de vegetais, frutas e produtos industrializados. Os CF ainda podem ser pigmentos, que fornecem a aparência colorida aos alimentos. Esses compostos agem como antioxidantes, não somente pela sua habilidade em doar hidrogênio ou elétrons, mas também devido a seus radicais intermediários estáveis, que impedem a oxidação de ingredientes do alimento, principalmente de lipídeos (SILVA et al., 2010).

\subsection{Atividade Larvicida frente ao Aedes aegypti}

Uma doença que está ganhando destaque nos noticiários e jornais é a dengue, doença infecciosa, de origem viral, é facilmente transmitida pela fêmea do mosquito do gênero Aedes. Por a mesma apresentar uma grande incidência nos países tropicais e subtropicais, é considerada pela Saúde Pública uma das maiores preocupações do mundo (WORL, 2004).

Já foi detectada em várias partes do mundo a grande resistência que o A. aegypti apresenta a inseticidas (LIMA et al., 2003). Mesmo com a comprovação desse fato, a população ainda continua fazendo uso de tais inseticidas sintéticos, e se deve ter cuidado com essa utilização descontrolada, uma vez que os mesmos tem contaminado o meio ambiente e os organismos vivos (RAIZADA et al.,2001). Frente a este problema, faz-se necessário a pesquisa e descoberta de produtos que venham a ser utilizados para este fim que não traga tantos impactos ambientais.

Frente a estes problemas, surge o interesse de estudos com extratos vegetais que busquem substâncias que apresentem propriedades inseticidas e que possam ser comercializadas (FURTADO, et al., 2005), uma vez que tais plantas podem apresentar compostos que apresentam atividade inseticida capaz de afetar processos característicos das pestes, como por exemplo, a perturbação do comportamento de alimentação, os reguladores de crescimento e o balanço endócrino (BALANDRIN, et al., 1985).

\subsection{Vitex gardneriana Schauer}

A Vitex gardneriana Schauer é popularmente conhecida por “jaramataia”, pertencente à família Verbenaceae, gênero Vitex. Grande parte das árvores pertencentes a essa família são encontradas no sertão do Nordeste, frequentemente encontradas às margens e leitos de rios (BARRETO, 2004).

Pela população, a espécie é utilizada pra diversos fins patológicos, como por exemplo: verminose, gripe, estalicido, gases, dor de barriga, sinusite, inflamação na próstata (ROQUE, 2009) e ainda para dor nos ossos, problemas nos rins, problema na coluna, calmante, dentre outros (ANDRADE et al., 2012).

\section{METODOLOGIA}

\subsection{Levantamento Bibliográfico}

Foi realizado um levantamento bibliográfico utilizando livros que remetessem ao assunto, bem como em artigos científicos, sites, utilizando como fonte o Scielo, google acadêmico, portal periódicos da CAPES, entre outros.

\subsection{Coleta e Classificação do Material Botânico}

A espécie vegetal Vitex gardneriana Schauer foi obtida na cidade de Apodi, por intermédio de moradores locais, que fizeram a coleta da mesma às margens do rio Apodi-Mossoró. O material vegetal constituiu-se apenas de folhas secas. 


\subsection{Preparação do Extrato Em Etanol}

As folhas secas foram picadas e colocados em um recipiente de vidro com etanol e deixado em contato por 7 dias. Após esse período o solvente foi filtrado e concentrado em um processo de rota evaporação sob pressão reduzida, obtendo assim o extrato em etanol.

\subsection{Preparação do Extrato em Água}

Após o preparo do extrato em etanol, as folhas foram colocados em contato com água também por um período de 7 dias. Em seguida, o solvente foi filtrado e concentrado em banho maria até a obtenção do extrato em água.

\subsection{Determinação da Atividade Antioxidante}

Em um tubo de ensaio foi colocado 1,0 mL de uma solução em metanol do radical livre DPPH $60 \mu \mathrm{M}$. Em seguida, foi adicionado ao tubo 1,0 mL da solução em metanol da amostra a ser testada nas concentrações de 5000 ppm a 10 ppm. A absorbância foi medida num espectrofotômetro de UV marca TEN-KA T-2000 no comprimento de onda de $520 \mathrm{~nm}$, depois de 30 minutos. A percentagem de inibição foi obtida por comparação da absorção da solução contendo amostra, em relação a uma solução controle de DPPH sem amostra (ALMEIDA et al., 2010). Todo o experimento foi realizado em triplicata. Para comparação dos valores das concentrações que inibem $50 \%$ dos radicais livres $\left(\mathrm{CI}_{50}\right)$ dos extratos foi feita uma curva de calibração utilizando o Trolox como padrão positivo.

\subsection{Determinação do Teor de Fenóis Totais}

Cada amostra vegetal foi dissolvida em metanol, em seguida transferido para um balão volumétrico de $100 \mathrm{~mL}$ e aferido com metanol. Em outro balão, de $50 \mathrm{~mL}$, foram transferidos 7,5 mL da solução inicial, na qual esta segunda solução teve seu volume acertado com metanol. Uma alíquota de $100 \mu \mathrm{L}$ desta última solução foi agitada com $500 \mu \mathrm{L}$ do reagente de Folin-Ciocalteu e $6 \mathrm{~mL}$ de água destilada por $1 \mathrm{~min}$. Após esse tempo foi adicionado $2 \mathrm{~mL}$ de carbonato de sódio $\left(\mathrm{Na}_{2} \mathrm{CO}_{3}\right) 15 \%$ a mistura e agitada por $30 \mathrm{~s}$. A solução teve seu volume acertado para $10 \mathrm{~mL}$ com água destilada. Após 2 h a absorbância das amostras foram medidas no espectrofotômetro de UV marca TEN-KA T-2000 no comprimento de onda de $750 \mathrm{~nm}$ (BONOLI et al., 2004). Os testes foram feitos em triplicata. Para determinação do teor de fenóis foi feita uma curva de calibração com padrões de ácido gálico (10 a 350 $\mu \mathrm{g} / \mathrm{mL}$ ) e expressos como mg de EAG (equivalentes de ácido gálico) por g de extrato.

\subsection{Determinação da Atividade Larvicida}

As cartelas dos ovos do Aedes aegypti foram fornecidas pela Secretaria de Saúde do Estado do Ceará. Essas cartelas foram postas em uma bandeja de poliestireno e adicionado agua da torneira para que as larvas eclodissem. Quando as larvas obtiveram o $3^{\circ}$ estágio (aproximadamente 3 a 4 dias) foi dado início ao experimento.

Foram pesados $10 \mathrm{mg}$ de cada amostra vegetal, separadamente, e dissolvidas em 0,3 $\mathrm{mL}$ de dimetilsulfóxido (DMSO). Em seguida, a essa mistura, foram adicionados um volume de água suficiente para completar $20 \mathrm{~mL}$ de solução a ser testada numa concentração de $500 \mathrm{ppm}$. Os testes foram realizados em triplicata, em que cada triplicata continha 25 larvas do Aedes aegypti no terceiro estágio. Para os extratos que provocaram uma boa mortalidade, foram realizados novos testes em concentrações menores (250, 100 e 50 ppm). Para o controle negativo utilizou-se somente água, o DMSO e as larvas. Os resultados foram registrados após 72 horas (COELHO; DE PAULA; ESPÍNOLA, 2009). Para a obtenção da $\mathrm{CL}_{50}$ foi utilizado o programa de estatística Origin 7.0.

\section{RESULTADOS E DISCUSSÕES}

Foram obtidos 12,546g do extrato em etanol das folhas (EEFSJ) e 7,760g do extrato em água (EAFSJ), resultando nos rendimentos que podem ser observados na Tabela 1. 
Tabela 1 - Massas e rendimentos dos extratos de Vitex gardneriana Schauer.

\begin{tabular}{ccc}
\hline MATERIAL & MASSA & RENDIMENTO \\
VEGETAL & & \\
\hline EEFSJ & $12,546 \mathrm{~g}$ & $13,12 \%$ \\
EAFSJ & $7,760 \mathrm{~g}$ & $8,13 \%$ \\
\hline
\end{tabular}

EEFSJ: Extrato em etanol das folhas secas de jaramataia;

EAFSJ: Extrato em água das folhas secas de jaramataia.

A Tabela 1 apresenta as massas e rendimentos dos extratos feitos com o material vegetal, e pode-se perceber o quanto o extrato em etanol tem um rendimento satisfatório, isso porque eles conseguem absorver diversos compostos que apresentam polaridades diferentes.

Com os extratos em etanol e em água foram realizados os testes para determinação da atividade atioxidante. Os resultados após a realização dessess testes podem ser observados na Tabela 2.

Tabela 2 - Atividade antioxidante obtida pelo método do DPPH dos extratos de Vitex gardneriana

\begin{tabular}{cc}
\multicolumn{2}{c}{ Schauer. } \\
\hline EXTRATO & $\mathbf{C I}_{\mathbf{5 0}}$ \\
\hline EEFSJ & $82,60 \mathrm{ppm}$ \\
EAFSJ & $145,04 \mathrm{ppm}$ \\
TROLOX & $4,07 \mathrm{ppm}$
\end{tabular}

EEFSJ: Extrato em etanol das folhas secas de jaramataia;

EAFSJ: Extrato em água das folhas secas de jaramataia.

O valor da concentração inibidora $\left(\mathrm{CI}_{50}\right)$ foi calculado a fim de se definir a concentração necessária para inibir o radical DPPH em 50\%. Ao se analisar a Tabela 2 e comparar os valores obtidos com o padrão positivo utilizado, o Trolox, nota-se que o extrato que apresentou uma melhor atividade antioxidante foi o em etanol das folhas secas.

Como esta espécie apresentou uma boa atividade antioxidante, e uma das classes que é conhecida por proporcionar tal atividade é a dos compostos fenólicos, resolveu-se fazer uma quantificação de tais compostos, através do teste do teor de fenóis totais nos extratos. Os testes foram realizados pelo método de Folin-Ciocalteau e os resultados expressos em equivalência de ácido gálico (EAG) por grama de extrato bruto. Os valores podem ser observados na Tabela 3.

Tabela 3 - Teor de fenóis totais obtido pelo método Folin-Ciocalteau dos extratos d e Vitex gardneriana Schauer.

\begin{tabular}{cc}
\hline EXTRATO & $\begin{array}{c}\text { FENÓIS TOTAIS (mg } \\
\text { EAG/g de extrato bruto) }\end{array}$ \\
\hline EEFSJ & 77,94 \\
EAFSJ & 92,85
\end{tabular}

EEFSJ: Extrato em etanol das folhas secas de jaramataia;

EAFSJ: Extrato em água das folhas secas de jaramataia.

Como se sabe existe uma relação direta entre a atividade antioxidante e o teor de fenóis totais, uma vez que quanto menor a $\mathrm{CI}_{50}$ da espécie vegetal é esperado que o teor de fenóis fosse maior, porém, é perceptível uma divergência, onde o extrato em etanol das folhas foi o que apresentou uma melhor atividade antioxidante, no entanto não foi o que mostrou o maior teor de fenóis. Esse fato pode ser atribuído a alguns interferentes, resultando nos testes falsos positivos, que é a influência de alguns fatores nos resultados dos mesmos, como: ausência de taninos, presença não significativas de flavonóides (SANTOS; BLATT, 1998) e presença de proteínas (SILVA, et al. 2010). 
Com os extratos ainda foram realizados também a determinação da atividade larvicida. Os resultados após a realização dos testes podem ser observados na Tabela 4.

Tabela 4 - Determinação da atividade larvicida frente ao Aedes aegypti dos extratos de Vitex gardneriana Schauer.

\begin{tabular}{cc}
\hline \multicolumn{1}{c}{ EXTRATO } & $\mathbf{C L}_{50}$ \\
\hline EEFSJ & $369,1 \mathrm{ppm}$ \\
EAFSJ & $(-)$ \\
\hline \multicolumn{2}{|c|}{ EEFSJ: Extrato em etanol das folhas secas de jaramataia; }
\end{tabular}

EAFSJ: Extrato em água das folhas secas de jaramataia.

Os resultados expressos na Tabela acima mostram que o extrato em etanol de $V$. gardneriana Schauer apresentou uma boa atividade larvicida, com a concentração letal que mata $50 \%$ das larvas de 369,1 ppm. Já no extrato em água, não foi possível determinar tal atividade.

Na literatura muitos trabalhos são encontrados a cerca da boa atividade larvicida de substâncias isoladas encontradas em óleos essenciais, como por exemplo o eugenol, que apresenta a $\mathrm{CL}_{50}$ de 44,5 ppm contra A. aegypti (SIMAS et al., 20014). Quando comparamos este valor com o encontrada no trabalho, pode-se constatar que a espécie estudada apresenta uma boa atividade, uma vez que o teste foi realizado com o extrato bruto e não com a substância isolada.

\title{
5 CONCLUSÃO
}

Mediante resultados obtidos, pode-se verificar que a planta em estudo apresentou valores bastante promissores. A atividade antioxidante, quando comparada com o padrão positivo, o TROLOX, foi considerada boa, apresentando a $\mathrm{CI}_{50}$ para o extrato em etanol de $82,60 \mathrm{ppm}$ e para o extrato em água de 145,04 ppm. Os extratos também apresentaram um bom teor de fenóis, com destaque para o extrato em água, com 92,85 mg de EAG/mg de extrato.

No que diz respeito a atividade larvicida frente ao A. aegypti, o extrato em etanol apresentou uma considerável atividade, com a $C_{50}$ de 369,1 ppm, já o extrtato em água não apresentou atividade. Vale ressaltar ainda, que estudos como este são de grande relevância, visto que na literatura não é possível encontrar muitos trabalhos relacionados a esta espécie vegetal, almeja-se ainda realizar outros testes com a mesma.

\section{ANTIOXIDANT ACTIVITY , PHENOLS CONTENT AND LARVICIDAL ACTIVITY FRONT Aedes aegypti OF Vitex gardneriana Schauer}

\begin{abstract}
The early use of natural products for various purposes occurred since many time ago, where the first civilizations were already using the same to relieve/cure diseases, and the population's interest for these products is growing increasingly. Faced with this, the study aims to determine the antioxidant activity, total phenolic content and larvicidal activity against Aedes aegypti of extracts in ethanol and water V. gardneriana Schauer, popularly known as jaramataia. The results for all three tests were satisfactory, since for the plant species antioxidant activity showed an $\mathrm{IC}_{50}$ of $82.60 \mathrm{ppm}$ and $145.04 \mathrm{ppm}$ for the extracts in ethanol and water, respectively. The extract water stood out as the phenol content, with $92.85 \mathrm{mg} \mathrm{GAE} / \mathrm{mg}$ extract. As for the activity Larvicide the only extract that showed activity, was in ethanol to LC50 of $369.1 \mathrm{ppm}$. In general the results were very promising.
\end{abstract}

Keywords: Antioxidant Activity; Phenols; Larvicide Activity; V. gardneriana Schauer. 


\section{REFERÊNCI AS BI BLIOGRÁFICAS}

AMES, B. N.; GOLD, L. S.; WILET, W. C. The causes and prevention of cancer. Proceedings of the National Academy of Sciences, U.S.A. v. 92, p. 5258-5265, 1995.

ANDRADE, S. E. O.; MARACAJÁ, P. B.; SILVA, R. A.; FREIRES, G. F.; PEREIRA, A. M. Estudo Etnobotânico De Plantas Medicinais na Comunidade Várzea Comprida dos Oliveiras, Pombal, Paraíba, Brasil. Revista Verde (Mossoró - RN), v. 7, n. 3, p. 46-52, jul-set, 2012.

ALMEIDA, M. C. S., ALVES, L. A., SOUZA, L. G. S., MACHADO, L. L., MATOS, M. C., OLIVEIRA, M. C. F., LEMOS, T. L. G., BRAZ-FILHO. Flavonoids and other substances from Lippia sidoides and their antioxidant activities. Química Nova, 33, 1877-1881, 2010.

ALVES, H.M. Plantas como fonte de fitofármacos. Cadernos Temáticos de Química Nova na Escola. $\mathrm{n}^{\circ}$ 3, p. 01-06. 2001.

AUST, O.; SIES, H.; STAHL, W.; POLIDORI, M.C. Analysis of lipophilic antioxidants in human serum and tissues: tocopherols and carotenoids. Journal of Chromatography., v. 936, n.1, p. 83-93, 2001.

BARRETO, L.C.L.S. Estudo farmacognóstico e determinação da atividade biológica de Vitex gardneriana Schauer (Verbenaceae). 2004. 114 p. Dissertação de Mestrado no estado de Recife, Brasil. Pela Universidade Federal de Pernambuco, Centro de Ciências da Saúde, Departamento de Ciências Farmacêuticas e Programa de Pós-Graduação em Ciências Farmacêuticas. Dissertação de Mestrado, 2004.

BALANDRI, M. F.; KLOCKE, J. A.; WURTELE, E. S.; BOLLINGER, W. H. Natural plant chemicals: source of industrial and medical materials. Science (Wash. D. C.) 228: 1154-1160. 1985.

BONOLI, M.; VERARDO, V.; MARCONI, E.; CABONI, M. F. Antioxidant Phenols in Barley (HordeumvulgareL.) Flour: Comparative Spectrophotometric Study Among Extraction Methods of Free and Bound Phenolic Compounds. Journal of Agricultural and Food Chemistry, vol. 52, p. 5195, 2004.

CALIXTO, J. B. Efficacy, safety, quality control, marketing and regulatory guidelines for herbal medicines (phytoterapeutic agents). Brazilian Journal of Medical and Biological Research, v. 33, p. 179-189, 2000.

CALIXTO, J. B. Twenty-five years of research on medicinal plants in Latin America: a personal review. Journal of Ethnofarmacology, v. 100, p. 131-134, 2005.

CARVALHO, A. C. B.; BALBINO, E.E.; MACIEL, A.; PERFEITO, J. P. S. Situação do registro de medicamentos fitoterápicos no Brasil. Revista Brasileira de Farmacognisia, v. 18, p. 314-319, 2008.

COELHO, A. A. M.; DE PAULA, J. E.; ESPÍNOLA, L.S. Insectcidal activity of cerrado plant extracts on Rhodnus milesi Carcavalho, Rocha, Galvão e Jurbeg (Hemiptera Reduviidae), under laboratory conditions. Neotropical Entomology. 35: 133-138. 2009.

CHRISTEN, Y. Oxidative stress and Alzheimer's disease. The American Journal of Clinical Nutrition, v. 71, n. 2, p. 621S-629S, 2000.

DIXON, R.A. Natural products and plant disease resistance. Nature, p.411-847, 2001.

FURTADO, R. F.; LIMA, M. G. A.; ANDRADE NETO, M.; BEZERRA, J. N. S.; SILVA, M. G. V. Atividade Larvicida de Óleos Essenciais Contra Aedes aegypti L. (Diptera: Culicidae). Neotropical Entomology. p. 843-847. 2005.

HANDELMAN, G.J. The evolving role of carotenoids in human biochemistry. Nutrition, v. 17, n. 10, p. 818-822, 2001.

LANG, A. E.; LOZANO, A. M. Parkinson's disease. First of two parts. The New England Journal of Medicine, v. 339, n. 16, p. 111-114, 1998. 
LIMA, C. T.; FRANÇA, F. FLORA DA BAHIA: Vitex Tour. ex L.- (LAMIACEAE). $60^{\circ}$ Congresso Nacional de Botânica - BA. 2009.

LIMA, J. B. P.; CUNHA, M. P.; SILVA JÚNIOR, R. C.; GALARDO, A. K. R.; SOARES, S. S.; BRAGA, I. A.; RAMOS, R. P.; VALLE, D. Resistance of Aedes aegypti to organophosphates in several Minicipalities in the state of Rio de Janeiro and Espírito Santo, Brazil. American Journal of Tropical Medicine and Hygien. 68:329-333. 2003.

OLIVEIRA, M.J.R; SIMÕES, M.J.S; SASSI, C.R.R. Fitoterapia no sistema de saúde publica (SUS) no Estado de São Paulo, Brasil. Revista Brasileira de Plantas Medicinais, Botucatu v. 8, n. 2, p. 3941, 2006.

RAIZADA, R. B.; SRIVASTANA, M. K.; KAUSHAL, R. A.; SINGH, R. P. Azadirachtin, a neem biopesticide: subchronic toxicity assessment in rats. Food and Chemical Toxicology. 39: 477-483. 2001.

ROESLER, R.; MALTA, L.G.; CARRASCO, L.C.; HOLANDA, R.B.; SOUZA, C.A.S.; PASTORE, G.M. Atividade Antioxidante de frutas do cerrado. Ciência e Tecnologia de Alimentos, Campinas, v. 27, n. 1, p. 53-60, jan.-mar., 2007.

ROQUE, A. A. Potencial de Uso dos Recursos Vegetais em uma Comunidade Rural do Semi-árido do Rio Grande do Norte. 2009. 79 f. Dissertação de Mestrado apresentada ao Programa de PósGraduação em Desenvolvimento e meio ambiente, pela Universidade Federal do Rio Grande do Norte para obtenção do Título de Mestre em Desenvolvimento e Meio Ambiente. 2009.

SANTOS, M. D.; BLATT, C. T. T. Teor de flavonóides e fenóis totais em folhas de Pyrostegia venusta miers de mata e de cerrado. Revista Brasileira de Botânica. Vol. 21, n. 2, p.135-40. São Paulo, ago. 1998.

SIMAS, N.K.; LIMA, E.C.; CONCEIÇÃO, S.R.; KUSTER, R.M.; OLIVEIRA, F.A.M. Produtos naturais para o controle da transmissão da dengue - atividade larvicida de Myroxylon balsamum (óleo vermelho) e de terpenóides e fenilpropanóides. Quím. Nova 27: 46-49. 2004.

SILVA, M.L.C.; COSTA, R.S.; SANTANA, A. S.; KOBLITZ, M. G. B. Compostos fenólicos, carotenóides e atividade antioxidante em produtos vegetais. Semina: Ciências Agrárias, Londrina, v. 31, n. 3, p. 669-682, jul./set. 2010.

VEIGA-JUNIOR, V.F.; MELLO, J. C. P. As monografias sobre plantas medicinais. Revista Brasileira de Farmacognosia, v. 18, p. 464-471, 2008.

WORLD HEALTH ORGANIZATION. Dengue bulletin: Situation of dengue/dengue haemorrhagic fever in SEA countries. 2004. 